\title{
Chronic progressive ankle pain
}

\author{
Zaid Jibri $^{1,2} \cdot$ Ryan Foster ${ }^{1,2} \cdot$ Kawan Rakhra ${ }^{1,2}$
}

Published online: 14 February 2017

(C) ISS 2017

\section{Diagnosis}

Accessory anterolateral talar facet

\section{Discussion}

In this case, MRI demonstrates the presence of an accessory facet of the talus, with overlying hyaline cartilage anterior to the lateral talar process. This facet is directly opposed to the surface of the calcaneal neck, which also has overlying hyaline cartilage, forming an articulation (Fig. 1). The cartilage along this accessory facet is in continuity with that of the posterior talar facet of the subtalar joint. There are small spurs at the margins of this accessory facet (Fig. 1a, b and d) with mild marrow edema on both sides of this articulation (Fig. 1c and d), indicative of an element of degeneration.

The clinical subtalar joint has three sets of articular facets between the talus and calcaneus, anterior, middle and posterior facets that can be separate or have different degrees of continuity between each other [1]. The posterior facet is the articulation between the posteroinferior aspect of the talar body and the posterosuperior aspect of the calcaneus. It lies immediately posterior to the sinus tarsi [2]. In 1904, Sewell first described accessory anterolateral talar facet (AALTF) as

The case presentation can be found at doi: 10.1007/s00256-017-2585-x.

\section{Zaid Jibri}

zaid.jibri@icloud.com

1 Department of Medical Imaging, The Ottawa Hospital, Ottawa, ON, Canada

2 Department of Radiology, University of Ottawa, Ottawa, ON, Canada

facies externa accessoria corporis tali in a study describing the osteology of the talus [3]. The term facet has been used in the literature to describe one side of an articulation covered by a layer of hyaline cartilage in joints such as the subtalar and zygapophyseal joints. The AALTF spreads contiguously from the posterior facet of the talus anterior to the lateral talar process with a layer of articular cartilage observed on the surface of the accessory facet $[4,5]$. AALTF was identified in 25$34 \%$ of the specimens in cadaveric studies [5-7]. An anterior calcaneal extension facet along the calcaneal neck opposing the AALTF was prevalent in $4 \%$ of the sample in a cadaveric study [5]. This study has also demonstrated that a large AALTF is found in $2.5 \%$ of the specimens [5]. A recent MRI study has found that AALTF is present in $32.7 \%$ of patients who have ankle symptoms and in $26 \%$ of asymptomatic volunteers [8]. AALTF can be symptomatic and has become increasingly recognized as a source of talocalcaneal impingement $[5,9,10]$. It is also associated with rigid flat foot deformity $[4,10]$. The latter entity is diagnosed clinically by demonstrating restricted subtalar motion, which may be painful. Peroneal spasm or contracture may also be noted with passive inversion [9]. MRI and CT were used to identify the accessory anterolateral talar facet in several clinical studies [6-8]. Bone marrow edema at the talar or calcaneal side as well as sinus tarsi fat edema is significantly more prevalent in symptomatic patients with AALTF [8]. It has been shown that, intraoperatively, the accessory facet has an overlying hyaline cartilage layer, often with cartilaginous thinning, fibrillation or defects $[4,10]$. Symptomatic patients not responding to conservative treatment can be treated surgically. AALTF resection with or without subtalar joint-sparing reconstructive procedures and soft-tissue reconstruction have been shown to provide good outcome with improvement in symptoms and function and improvement in the radiographic parameters associated with adult acquired flat foot deformity $[4,9,10]$. 
Histologically, the resected facets demonstrated areas of normal hyaline cartilage with intermittent areas of chondral thinning and fissuring, early fibrocartilaginous changes and thickened subchondral bone with cyst formation [9]. The patient in the presented case has been seen by the ankle and foot specialist in our institution, and the clinician plan is to offer him a trial of local corticosteroid injection versus surgery (AALTF resection).

\section{Compliance with ethical standards}

Conflict of interest The authors declare that they have no conflict of interest.

\section{References}

1. Jung MH, Choi BY, Lee JY, Han CS, Lee JS, Yang YC, et al. Types of subtalar joint facets. Surg Radiol Anat. 2015;37(6):629-38.

2. Linklater J, Hayter CL, Vu D, Tse K. Anatomy of the subtalar joint and imaging of talo-calcaneal coalition. Skelet Radiol. 2009;38(5): 437-49.
3. Sewell RB. A study of the astragalus. J Anat Physiol. 1904;38(Pt 4):423-34.

4. Niki H, Hirano T, Akiyama Y, Beppu M. Accessory talar facet impingement in pathologic conditions of the peritalar region in adults. Foot Ankle Int. 2014;35(10):1006-14.

5. Martus JE, Femino JE, Caird MS, Hughes RE, Browne RH, Farley FA. Accessory anterolateral facet of the pediatric talus. An anatomic study. J Bone Joint Surg Am. 2008;90(11):2452-9.

6. Hirano T, Niki H, Akiyama Y, Beppu M. Anatomical characteristics of the accessory antero-lateral talar facet. J Orthop Sci. 2015;20(1): 124-8.

7. Hattori K, Sakuma E, Nakayama M, Kozaki A, Wada I, Otsuka T. An anatomic study of the accessory anterolateral talar facet. Folia Morphol (Warsz). 2015;74(1):61-4.

8. Aydingoz U, Melih Topcuoglu O, Gormez A, Cankurtaran T, Dilara Topcuoglu E, Bilge Ergen F. Accessory anterolateral talar facet in populations with and without symptoms: prevalence and relevant associated ankle MRI findings. AJR Am J Roentgenol. 2016:1-6

9. Martus JE, Femino JE, Caird MS, Kuhns LR, Craig CL, Farley FA. Accessory anterolateral talar facet as an etiology of painful talocalcaneal impingement in the rigid flatfoot: a new diagnosis. Iowa Orthop J. 2008;28:1-8.

10. Niki H, Aoki H, Hirano T, Akiyama Y, Fujiya H. Peroneal spastic flatfoot in adolescents with accessory talar facet impingement: a preliminary report. J Pediatr Orthop B. 2015;24(4):354-61. 